\title{
MUC4 is not expressed in cell lines used for live cell imaging
}

\section{[version 1; peer review: 2 approved]}

\author{
Naouel Athmane (D), Iain Williamson, Shelagh Boyle, Simon C. Biddie (D), \\ Wendy A. Bickmore (iD
}

MRC Human Genetics Unit, Institute of Genetics and Cancer, University of Edinburgh, Edinburgh, Scotland, EH42XU, UK

V1 First published: 13 Oct 2021, 6:265

https://doi.org/10.12688/wellcomeopenres.17229.1

Latest published: 19 Nov 2021, 6:265

https://doi.org/10.12688/wellcomeopenres.17229.2

\section{Abstract}

Background: The ability to visualise specific mammalian gene loci in living cells is important for understanding the dynamic processes linked to transcription. However, some of the tools used to target mammalian genes for live cell imaging, such as dCas9, have been reported to themselves impede processes linked to transcription. The MUC4 gene is a popular target for live cell imaging studies due to the repetitive nature of sequences within some exons of this gene.

Methods: We set out to compare the impact of dCas9 and TALE-based imaging tools on MUC4 expression, including in human cell lines previously reported as expressing MUC4.

Results: We were unable to detect MUC4 mRNA in these cell lines. Moreover, analysis of publicly available data for histone modifications associated with transcription, and data for transcription itself, indicate that neither MUC4, nor any of the mucin gene family are significantly expressed in the cell lines where dCas9 targeting has been reported to repress MUC4 and MUC1 expression, or in the cell lines where dCas13 has been used to report MUC4 RNA detection in live cells. Conclusions: Methods for visualising specific gene loci and gene transcripts in live human cells are very challenging. Our data suggest that care should be given to the choice of the most appropriate cell lines for these analyses and that orthogonal methods of assaying gene expression be carefully compared.

Keywords

dCas9, imaging, mucin, transcription

\section{Open Peer Review}

Approval Status

1

2

version 2

(revision)

19 Nov 2021

version 1

13 Oct 2021

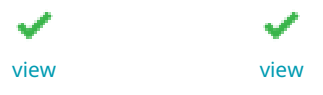

1. Thomas Sexton ID, Université de

Strasbourg, Strasbourg, France

2. Jonathan Chubb, University College London,

London, UK

Any reports and responses or comments on the article can be found at the end of the article. 
Corresponding author: Wendy A. Bickmore (Wendy.Bickmore@ed.ac.uk)

Author roles: Athmane N: Data Curation, Formal Analysis, Methodology, Resources, Writing - Review \& Editing; Williamson I: Methodology, Supervision, Validation; Boyle S: Investigation, Methodology, Validation; Biddie SC: Formal Analysis, Validation, Writing Review \& Editing; Bickmore WA: Conceptualization, Funding Acquisition, Project Administration, Supervision, Writing - Original Draft Preparation, Writing - Review \& Editing

Competing interests: No competing interests were disclosed.

Grant information: NA was supported by a PhD studentship from the MRC National Productivity Investment Fund. SCB is supported by a postdoctoral clinical lectureship from NES/ Chief Scientist Office. WAB is supported by Wellcome [212203,

https://doi.org/10.35802/217120] and by an MRC MRC University Unit grant (MC_UU_00007/2).

The funders had no role in study design, data collection and analysis, decision to publish, or preparation of the manuscript.

Copyright: @ 2021 Athmane $\mathrm{N}$ et al. This is an open access article distributed under the terms of the Creative Commons Attribution License, which permits unrestricted use, distribution, and reproduction in any medium, provided the original work is properly cited.

How to cite this article: Athmane N, Williamson I, Boyle S et al. MUC4 is not expressed in cell lines used for live cell imaging [version 1; peer review: 2 approved] Wellcome Open Research 2021, 6:265 https://doi.org/10.12688/wellcomeopenres.17229.1

First published: 13 Oct 2021, 6:265 https://doi.org/10.12688/wellcomeopenres.17229.1 


\section{Introduction}

Live cell imaging of actively transcribing genes allows investigation of the changes in chromatin dynamics associated with gene expression. However, achieving this involves multiple technical challenges and has, to date, resulted in contradictory conclusions likely due to the different approaches used for visualising the loci under investigation.

Live imaging studies of genomic loci in mammalian cells have mainly targeted repetitive elements. Initial studies relied on the insertion of repetitive arrays of bacterial operators $(\mathrm{LacO}$, tetO, $\mathrm{CuO}$ ) into the mouse or human genome and visualisation using the corresponding binding proteins (lacI, TetR, CymR) (Alexander et al., 2019; Chubb et al., 2002; Pollex \& Heard, 2019). Repeats are easier to visualise because they help to accumulate many fluorescent molecules in one spot, producing a high signal to noise ratio. The orthogonal ANCHOR system uses insertion of a short ANCH sequence and then spreading of the bacterial ParB protein, seeded at these binding sites, to enhance the signal (Germier et al., 2017). However, these approaches raise concerns about alteration of the chromatin and epigenetic state of the tagged loci caused by the insertion of bacterial DNA sequences. (Jacome \& Fernandez-Capetillo, 2011; Osorio-Valeriano et al., 2019).

More recently, directed binding by catalytically dead Cas9 (dCas9) and transcription-activator like effectors (TALEs) have been used to visualise telomeres, centromeres, sub-telomeric and pericentromeric repeats (Ma et al., 2016) or SINE elements in mammalian cells (Chen et al., 2013; Knight et al., 2015; Miyanari et al., 2013). These approaches do not rely on modifying the genomic locus under investigation.

However, the goal has been to image specific gene loci - not just repetitive elements. Various approaches, such as the use of multiple sgRNAs and fluorescently-tagged dCas9 (Gu et al., 2018), or the recruitment of multiple tagged proteins to sgRNAs (Cheng et al., 2016; Qin et al., 2017) have been used to overcome the signal:noise problem. In addition, the MUC4 gene has become a popular locus targeted for live cell visualisation due to a repetitive region in one of its exons (Chen et al., 2013).

However, dCas9 has been reported to inhibit both gene expression when bound at a gene locus (Chen et al., 2013), and the binding of endogenous transcription factors (Gao et al., 2014) (Shariati et al., 2019). Understanding how current live cell imaging tools impact gene expression is therefore an important aim. We set out to compare dCas9 and TALE based imaging to visualise the MUC4 locus in human cell lines in order to assess the impact of dCas 9 and TALE binding on the ability of the targeted locus to be transcribed. However, this work led us to question whether the cell lines commonly used for imaging MUC4 are an appropriate background on which to investigate $M U C 4$ expression.

Our experimental data and our bioinformatic analysis of publicly available data suggest that neither MUC4, MUC1 or indeed any member of the mucin gene family, are expressed at significant levels in the cell lines that have been previously used either to study dCas9-mediated repression of MUC4/MUC1 expression, or to visualise MUC4 RNA in the nucleus.

\section{Methods}

Cell culture and transfections

U2OS cells were grown in McCoy's 5A supplemented with $10 \%$ fetal bovine serum (FBS) and Penicillin/Streptomycin. Transfections were performed using Lipofectamine 3000 reagent (Invitrogen) following the manufacturer's recommendations. Briefly, 90\% confluent U2OS were transfected in a 6-well plate with $1 \mu \mathrm{g}$ of plasmid and $3,75 \mu \mathrm{l}$ of lipofectamine and $4 \mu \mathrm{l}$ of P3000 reagent. dCas9-EGFP or MUC4 targeting TALE-EGFP were transiently transfected into U2OS cells prior to imaging and RNA extraction. Transient transfection of sgRNAs in pSLQ1651 was monitored by mCherry expression.

\section{DNA FISH}

FISH on metaphase arrested U2OS cells was performed as previously described (Fantes et al., 1992). Fosmid WI2-1916J7 (chr3:195764450-195798680; hg38) was used to detect MUC4 exon 2 and was directly labelled with ChromaTide Alexa Fluor 594-5-dUTP (Thermofisher scientific C11400) by nick translation. 200ng of labelled probe were used per slide, with 8ug human CotI DNA (Invitrogen, cat\#18440-016) and 10ug sonicated salmon sperm DNA (Sigma, cat\#31149) and denatured in hybridization mix at $70^{\circ} \mathrm{C}$ for five minutes, then preannealed at $37^{\circ} \mathrm{C}$ for 15 minutes. The probe was then hybridized to the denatured slides in a humid chamber at $37^{\circ} \mathrm{C}$ overnight (approximately 16 hours). Slides were washed for $4 \times 3$ minutes in $2 \times S S C$ at $45^{\circ} \mathrm{C}$, then $0.1 \times S S C$ at $60^{\circ} \mathrm{C}$. Slides were counterstained in $0.5 \mu \mathrm{g} / \mathrm{ml}$ DAPI and mounted using Vectashield prior to imaging.

\section{dCas9 and TALE MUC4 targeting constructs}

A TALE binding domain targeting MUC4 was assembled simultaneously using Golden Gate Assembly of Esp3I digested fragments. Four modules from RVD encoding plasmids (Addgene kit \#1000000024) based on the MUC4 targeting RVDI to IV described by Ren et al. (2017) were assembled into a pTAL-spec-puro-eGFPmodified vector by thermocycling $\left(\left(37^{\circ} \mathrm{C} \quad 10\right.\right.$ mins, $\left.\left.16^{\circ} \mathrm{C} 10 \mathrm{mins}\right) \times 12\right), 36^{\circ} \mathrm{C} 15 \mathrm{mins}, 80^{\circ} \mathrm{C}$ 5 mins. RVDI(CCTG), RVDII (TCAC), RVDIII (CGAC), RVD IV (ACT). Golden Gate products were transformed into E. coli and selected on spectinomycin plates. Colonies screened for fully assembled TALEs by PCR were confirmed by Sanger sequencing and by a diagnostic digestion with NotI and BamHI.

The sgRNA targeting MUC4 expressed under control of the U6 promoter (pSLQ 1661-sgMUC4 - E3(F+E)) was generated by Chen et al. (2013) and ordered from Addgene (addgene \#51025). This was co-transfected into U2OS cells together with dCas9-EGFP-NLS plasmid.

\section{RNA extraction and cDNA synthesis}

To quantify gene expression when targeting MUC4, dCas9EGFP and TALE-EGFP expressing cells were harvested $24 \mathrm{~h}$ after gRNA transfection. RNA was extracted from 
approximately $1 \times 10^{6}$ cell pellets using the RNeasy mini kit (Qiagen 74106) as per the manufacturer's instruction, including an on-column DNase digestion (Qiagen 79254), eluted in $20 \mu \mathrm{L}$ ddH2O and quantified using the Qubit RNA broad range assay (ThermoFisher Q10210) with the Qubit 4 fluorometer. cDNA was synthesised from $2 \mu \mathrm{g}$ RNA using Superscript II reverse transcriptase (Invitrogen 18064071) primed with random hexamers in a final volume of $20 \mu \mathrm{l}$ (Promega C1181) as per the manufacturer's instructions.

\section{RT-qPCR}

For real-time (q)RT-PCR analysis of MUC4 expression in U2OS cells (Figure 3A and B), qPCR was carried out on the BioRad CFX96 Real-Time System as follows: For a final volume of $10 \mu \mathrm{l}$, three technical replicates were prepared together for each sample: $17.5 \mu \mathrm{l}$ of Light cycler 480 SYBR green I master (Roche 04887352001) $+10.5 \mu 11 \mu \mathrm{M}$ primer mix of forward and reverse primer $+7 \mu \mathrm{cDNA}$ (diluted 1:4). A standard curve was included for each primer set. Thermal cycler conditions were $44 \mathrm{PCR}$ cycles $\left(95^{\circ}\right.$ for $5 \mathrm{~min}, 95^{\circ}$ for $10 \mathrm{~s}, 60^{\circ}$ for $10 \mathrm{~s}, 72^{\circ}$ for $20 \mathrm{~s}$ ). Primer sequences used for qRT-PCR were:

MUC4 (Chen et al., 2013) (Figure 1B)

Fw: 5' TCAATGGTGGTCGTGTGATt 3'

Rv: 5' AAGTCGGTGCAGCTGTCTCT 3'

$\beta$-actin

Fw 5' CATGTACGTTGCTATCCAGGC 3'

Rv 5' CTCCTTAATGTCACGCACGAT 3'
Gene expression data were analysed for transfected cells (TALE or dCas9) vs mock transfected cells, normalised to $\beta$-actin by the $\left(2^{\left.-\triangle 4 C_{T}\right)}\right.$ method (Livak \& Schmittgen, 2001) as follows:

$\Delta \Delta C_{T}=\left[\left(C_{T} M U C 4-C_{T} \beta\right.\right.$ actin $)$ transfected $-\left(C_{T} M U C 4-C_{T} \beta\right.$ actin $)$ mock $]$

\section{RT-PCR}

First strand product was amplified by PCR using primers spanning between exon 3 and exon 4 of MUC4 for 35 cycles $\left(95^{\circ} \mathrm{C}\right.$ for $20 \mathrm{~s}, 60^{\circ} \mathrm{C}$ for $30 \mathrm{~s}, 72^{\circ} \mathrm{C}$ for $30 \mathrm{~s}$ ) and products visualised by agarose gel electrophoresis (Figure 3C). A -RT control was included. Primer sequences were:

\section{MUC4 (Figure 1C):}

Fw: 5' CACAACCTCCCAGACCATCAT 3'

Rv: 5' GGAAGAGGGAAACTCCTCTCTCA 3'

$\beta$-actin:

Fw 5' AGAGCTATGAGCTGCCTGACG 3'

Rv 5' TGTGTTGGCATAGAGGTCTTTACG 3'

Image acquisition

U2OS cells growing on slides were fixed with $4 \%$ paraformaledhyde, permeabilised with Triton X-100 and DAPI stained $24 \mathrm{~h}$ following transfection with dCas9 or TALE constructs. Slides were imaged using a Photometrics Coolsnap HQ2 CCD camera and a Zeiss AxioImager A1 fluorescence microscope with a Plan Apochromat 100x 1.4NA objective,
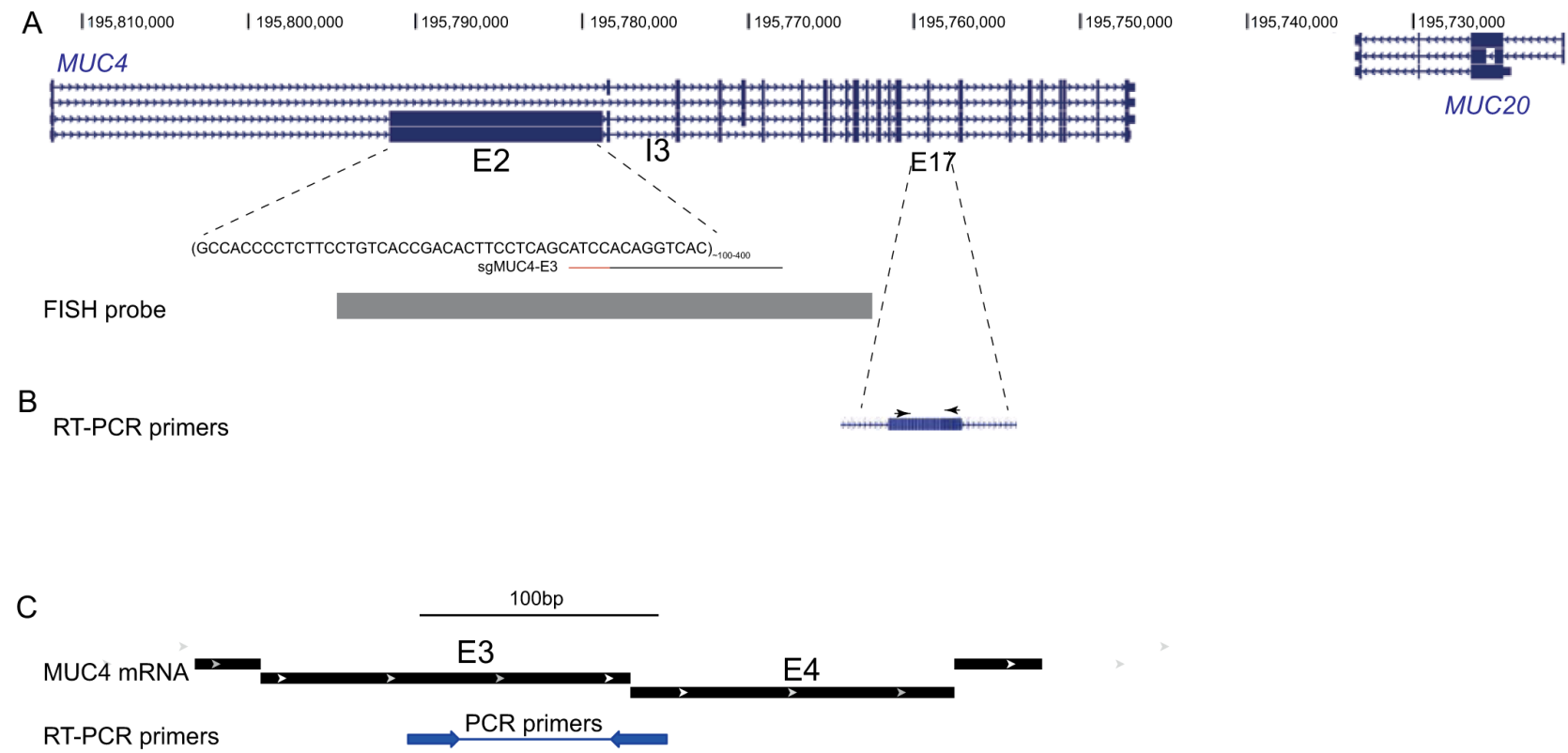

Figure 1. The MUC4 locus. (A) UCSC Genome Browser screen shot of the MUC4/MUC20 region on human chromosome 3. The location of the two repeated regions in exon2 (E2) and intron3 (I3) of MUC4 are indicated. The target sequence (black line) and the PAM (red line) of sgMUC4-E3 for targeting of dCas9 to E2 of MUC4 are shown. At the bottom, the position of the probe used for FISH is indicated. (B) Location of primers (arrowheads) located within exon 17 used for RT-PCR analysis of MUC4 expression by Chen et al. (2013). (C) Location of primers (arrowheads) spanning an exon-exon junction used here for RT-PCR analysis of MUC4 mRNA expression (mRNA transcript variant used for design: NCBI Reference Sequence: NM_004532.6). 
a Nikon Intensilight Mercury based light source (Nikon UK Ltd, Kingston-on-Thames, UK) and Chroma \#89014ET (3 colour) single excitation and emission filters (Chroma Technology Corp., Rockingham, VT) with the excitation and emission filters installed in Prior motorised filter wheels. A piezoelectrically driven objective mount (PIFOC model P-721, Physik Instrumente $\mathrm{GmbH} \& \mathrm{Co}$, Karlsruhe) was used to control movement in the $\mathrm{z}$ dimension. Step size for $\mathrm{z}$ stacks was set to $0.2 \mu \mathrm{m}$. Hardware control and image capture were performed the acquisition module or Nikon Nis-Elements software (Nikon UK Ltd, Kingston-on-Thames, UK).

\section{Bioinformatic analysis of gene expression}

ENCODE chromatin immunoprecipitation (ChIP)-seq data from U2OS cells were obtained from NCBI GEO: H3K4me3 (GSM871043), H3K36me3 (GSM788076).

For mature and nascent RNA-seq analysis from cell lines, publicly available data were obtained as indicated in Table 1. FastQ files were aligned to human genome hg38 using Bowtie. 2 with default settings. BAM files were then used to generate BigWig files using bamCoverage with normalisation across samples by scaling to $1 \mathrm{X}$ genome size.

To analyse mucin gene family expression, transcripts per million (TPM) data from RNA-seq datasets for 934 cell lines were obtained from the EBI-EMBL Expression Atlas data release 37. A heatmap was generated using pheatmap with TPM counts expressed as a Z-score. Cell lines were assigned an organ origin type with clustering using the default clustering method.

\section{Table 1. Sources of mRNA and nascent RNA-seq data for} Capan-1 and 2 cells, U2OS, RPE1, HeLa and HT1080 cells.

\begin{tabular}{|l|l|l|l|}
\hline $\begin{array}{l}\text { Cell } \\
\text { line }\end{array}$ & RNA & GSE Series & SRA Number \\
\hline Capan-1 & mRNA & GSE79669 & SRR3308945 \\
\hline Capan-2 & mRNA & GSE79669 & SRR3308945 \\
\hline U-2OS & mRNA & GSE162163 & SRR13142368 \\
\hline RPE1 & mRNA & GSE98541 & SRR5508027 \\
\hline HeLa & mRNA & GSE90235 & SRR5048095 \\
\hline HT1080 & mRNA & GSE78653 & SRR3192620 \\
\hline U-2OS & 4SU-seq (4-thiouridine) & GSE162264 & SRR13159400 \\
\hline RPE1 & EU-seq (5-ethynyl uridine) & GSE137448 & SRR10119526 \\
\hline HeLa & 4SU-seq (4-thiouridine) & GSE128753 & SRR8775198 \\
\hline
\end{tabular}

\section{Results}

Detection of the MUC4 locus in U2OS cells

MUC4 is the most common mammalian gene targeted for visualisation in live cells as its coding sequence has a variable number $(>100)$ of a $48 \mathrm{nt}$ tandem repeat in exon 2 . This 7.5 to $19 \mathrm{~kb}$ repeat region results in the translation of a 550 to $930 \mathrm{kDa}$ protein (Chaturvedi et al., 2008). The MUC4 locus also contains 90 repeats of a 15 bp sequence in intron 3 (Chen et al., 2013) (Figure 1).

Because dCas9 and TALE targeting approaches have been shown to have very different efficiencies with regard to the synthetic activation and repression of gene loci (Gao et al., 2014), we aimed to target dCas9-GFP or TALE-GFP to the MUC4 locus in human cell lines with the aim of assaying the chromatin dynamics of this locus when transcriptionally active.

There have been various reports visualising MUC4 in live U2OS cells (Chen et al., 2013; Qin et al., 2017). We therefore chose this bone osteosarcoma epithelial cell line for our initial studies. We targeted dCas9, to the MUC4 locus using a sgRNA (Figure 1A) previously designed for exon 2 (Chen et al., 2013). We also designed TALE proteins that target exon 2 of MUC4.

U2OS cells are reported to be hypertriploid. We confirmed this for chromosome 3q, where MUC4 is located, using DNA FISH (Figure 2A) with a probe that encompasses exon 3 (Figure 1A). MUC4-specific dCas9+sgRNA as well as TALE-GFP constructs were then transfected into U2OS cells. Foci were detected with both dCas9 and TALES. However, whilst 3 spots per nucleus were detected by the dCas9, consistent with the presence of three copies of the locus detected by DNA FISH (Figure 2B), up to 6 spots per nucleus were detected with the TALE-GFPs leading us to question what the TALE constructs were detecting.

MUC4 is not expressed in U2OS, RPE or HeLa cells

Since it has been previously reported that targeting dCas 9 to exon 2 of MUC4 leads to partial repression of MUC4 expression (Chen et al., 2013), we wished to assay whether MUC4 expression is impacted similarly by the binding of TALEs or dCas9 in U2OS cells. We performed real-time (q)RTPCR using the previously reported MUC4 qRT-PCR primers (Chen et al., 2013). Whilst there was some modest reduction in the concentration of the MUC4 amplicons from dCas9 and TALE-transfected cells relative to mock transfected cells, this was variable between biological replicates, especially for dCas9 (Figure 3A). However, Ct values for MUC4 amplification were very high compared with the $\beta$-actin control (Figure $3 \mathrm{~B}$ ) suggesting that MUC4 expression levels may be very low in this cell line and therefore that the qRT-PCR results may be unreliable. We also noted that the previously reported (Chen et al., 2013) MUC4 qRT-PCR primers are located entirely within exon 17 (Figure 1B) making it hard to exclude 
A
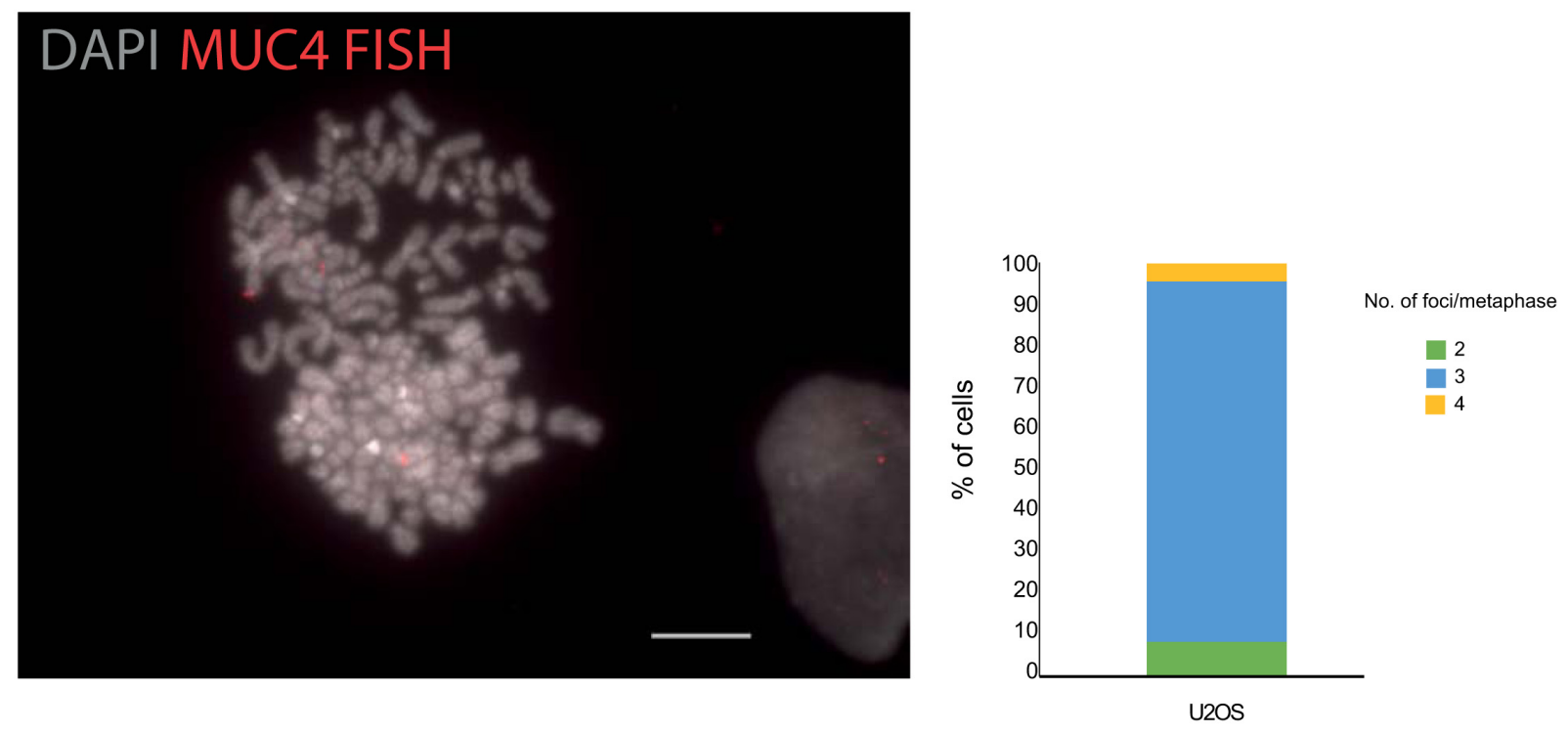

B
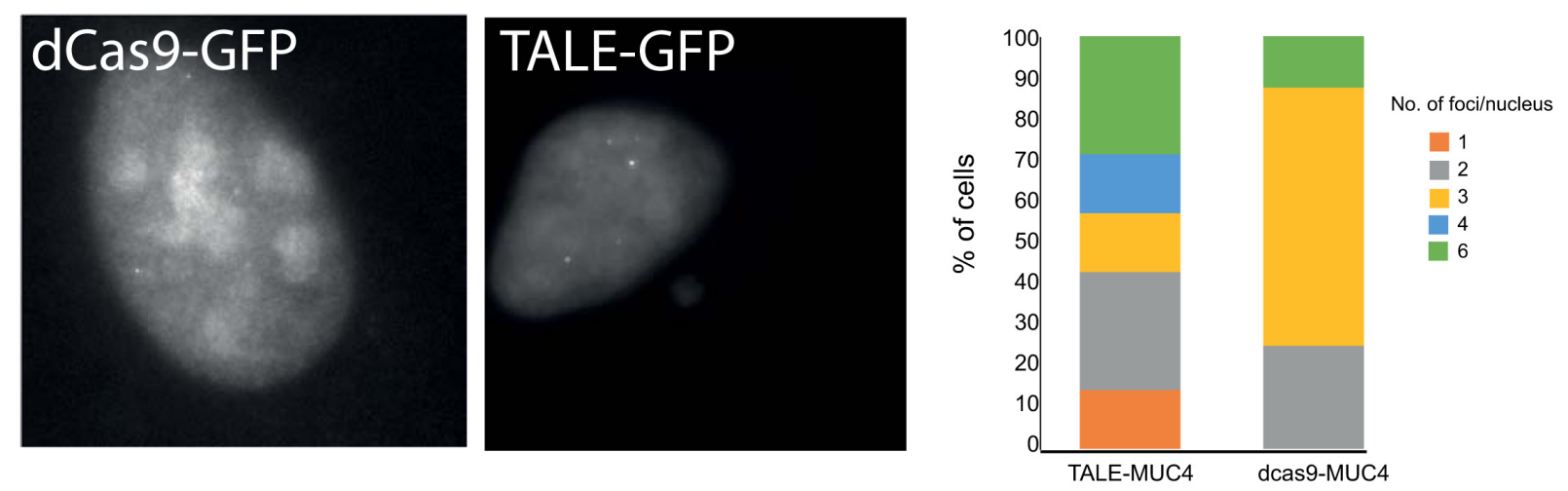

Figure 2. Detection of the MUC4 locus. A) Representative FISH image of a U2OS DAPI-stained metaphase chromosomes hybridised with the MUC4 fosmid probe (red) and indicating three copies of the locus. Scale bar=10 $\mu \mathrm{m}$. The graph to the right shows the number of loci detected per spread ( $n=23$ metaphase spreads). B) Images of GFP fluorescence in fixed U2OS cells transiently expressing either dCas9gRNA or TALE constructs specific to the MUC4 locus. The graphs to the right quantify the number of spots observed in transfected cells for either dCas9 or TALE.

genomic DNA contamination, or to distinguish spliced from unspliced transcripts. Indeed, we obtained the same $\mathrm{Ct}$ values with these MUC4 primers in U2OS RNA samples + or -RT.

We therefore also designed RT-qPCR primers which span across the exon 3-exon 4 junction of the MUC4 mRNA (Figure 1C). MUC4 encodes for a mucin, a transmembrane glycoprotein which is an important constituent of mucus. It is expressed by epithelial cells in the airway, the cervix, and the colon and is aberrantly expressed in some cancers (Chaturvedi et al., 2008). We therefore used RNA from human colonic mucosa tissue as a positive control for MUC4 expression. RT-PCR detects a strong $\sim 110 \mathrm{bp} \mathrm{MUC4}$ band in the colonic mucosa sample but not in U2OS cells (Figure 3C). There are multiple alternatively spliced isoforms of MUC4 (Figure 1), therefore it is possible that we were unable to detect the isoforms expressed in U2OS cells using the primers designed for RT-PCR.

Tri-methylation of histone H3K36 (H3K36me3) occurs co-transcriptionally and is enriched over the exons of expressed genes (de Almeida et al., 2011; Kim et al., 2011). Analysis of ENCODE ChIP-seq data for H3K36me3 in U2OS cells shows an absence of $\mathrm{H} 3 \mathrm{~K} 36 \mathrm{me} 3$ from $M U C 4$, from the adjacent $M U C 20$ gene on chromosome 3 (Figure 3D) and from $M U C 1$ located on human 1 (Figure 3E) in contrast to the neighbouring non-mucin genes. We therefore conclude that the mucin gene family, and particularly MUC4 is not expressed in U2OS cells. 

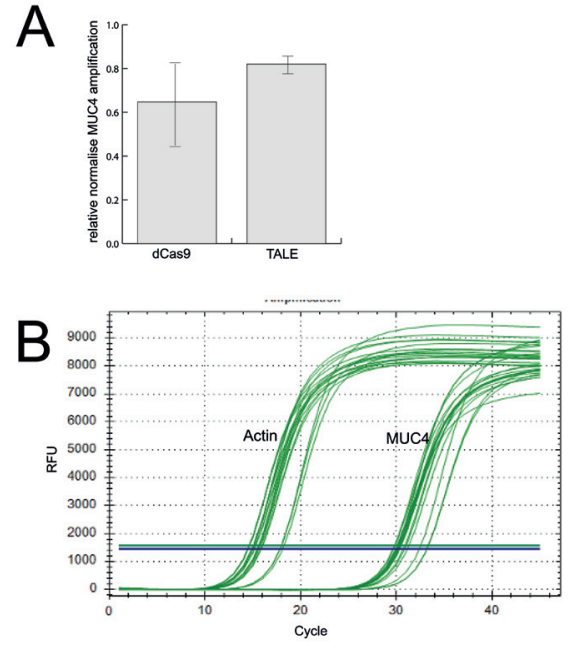

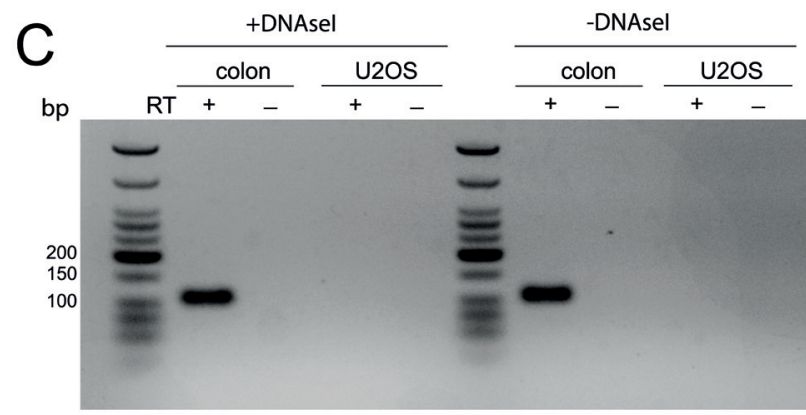

MUC4

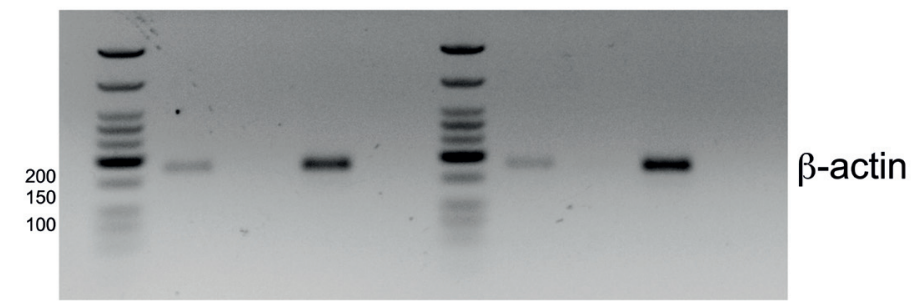

$195,800,0001$

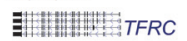
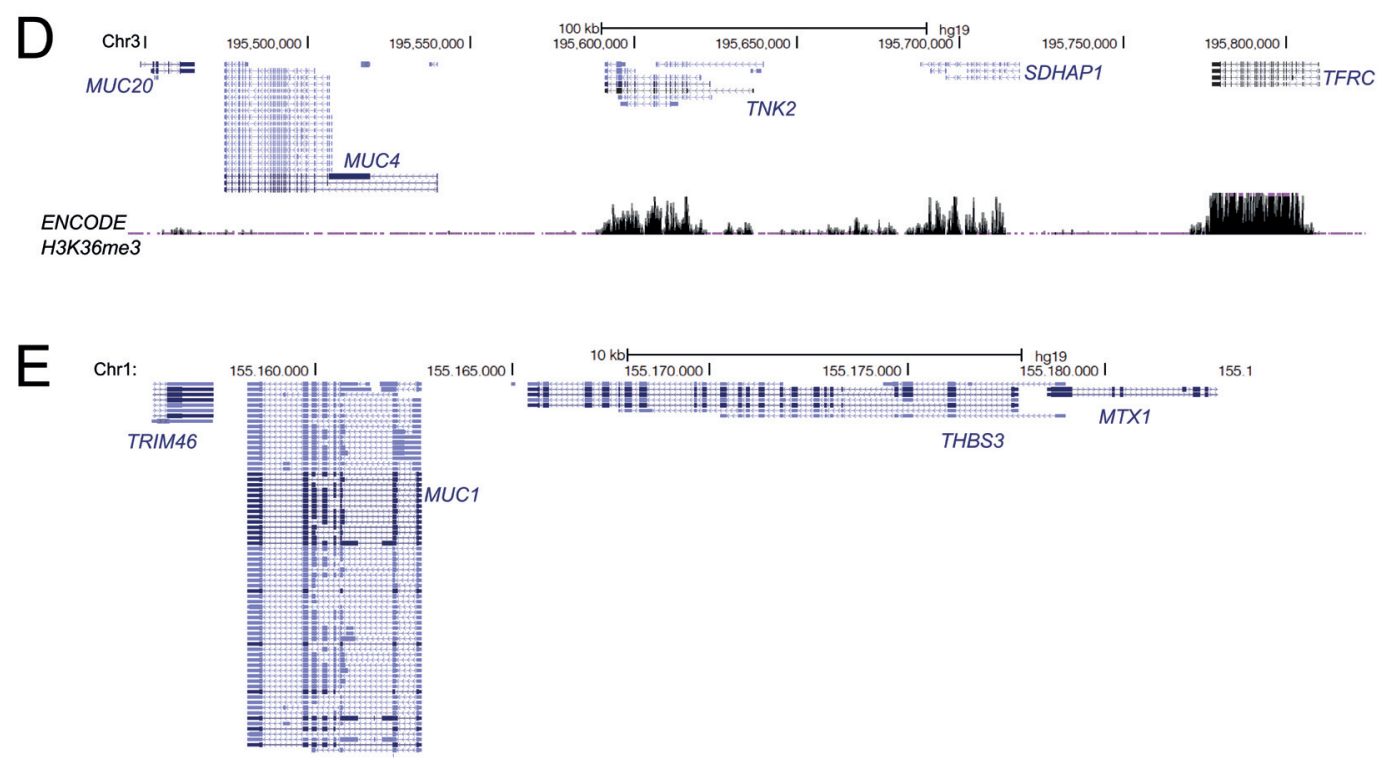

ENCODE

HЗK36me3
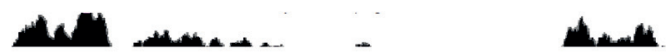

Figure 3. No evidence of MUC4 expression in U2OS cells. A) qRT-PCR data for MUC4 showing amplification levels in cells transfected with dCas9 and TALEs targeting MUC4, relative to mock transfected cells (2- $\triangle \mathrm{Act}$ ) and normalised to $\beta$-actin. Primers are those described by Chen et al. (2013) and shown in Figure 1B. Data show means (+/- stdev) from three biological replicates. B) Graph showing the rise in amplified product concentration with increasing cycle number for $\beta$-actin and for MUC4. Data shown are from three technical replicates of one of the three biological replicates used in (A). C) RT-PCR using the primers shown in Figure 1C to detect the expression of MUC4 (top) in RNA prepared from U2OS cells and human colon mucosa. Amplification of $\beta$-actin (bottom) acts as a positive control. - reverse transcriptase (RT) and DNAse I untreated samples act as controls for the presence of genomic DNA contamination in RNA samples. D and E) UCSC Genome Browser screen shot of the genomic regions containing the MUC20/MUC4 (D) and MUC1 (E) loci and adjacent non-mucin genes. Shown below is the ENCODE H3K36me3 ChIP-seq track from U2OS cells (GEO Accession number GSM788076). Genome co-ordinates are from the hg19 assembly of the human genome.

The live cell imaging study of the MUC4 locus (Chen et al., 2013) used the human retinal pigment epithelium (RPE) cell line, and reported that targeting dCas9 to exon 2 of MUC4 led to partial repression of MUC4 expression as assayed by qRT-PCR. Very significant $(70-80 \%)$ repression of expression was also reported for targeting of $M U C 1$ with dCas9. This implies expression of the mucin genes in this cell line, which is surprising given the origin of these cells from the pigmented epithelium at the back of the eye.

To investigate this further, we searched publicly available RNA-seq datasets from RPE cells. No mature MUC4, MUC20 (Figure 4A) or $\mathrm{MUCl}$ (Figure 4B) mRNAs were detected in these RPE datasets (Figure 4A), making it hard to understand 
A

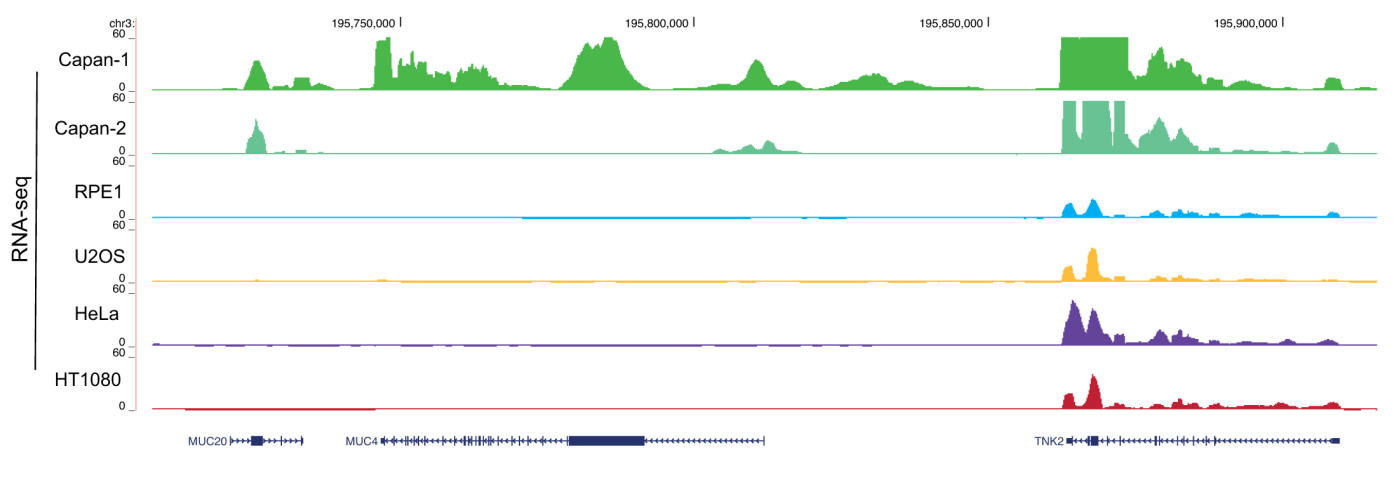

B

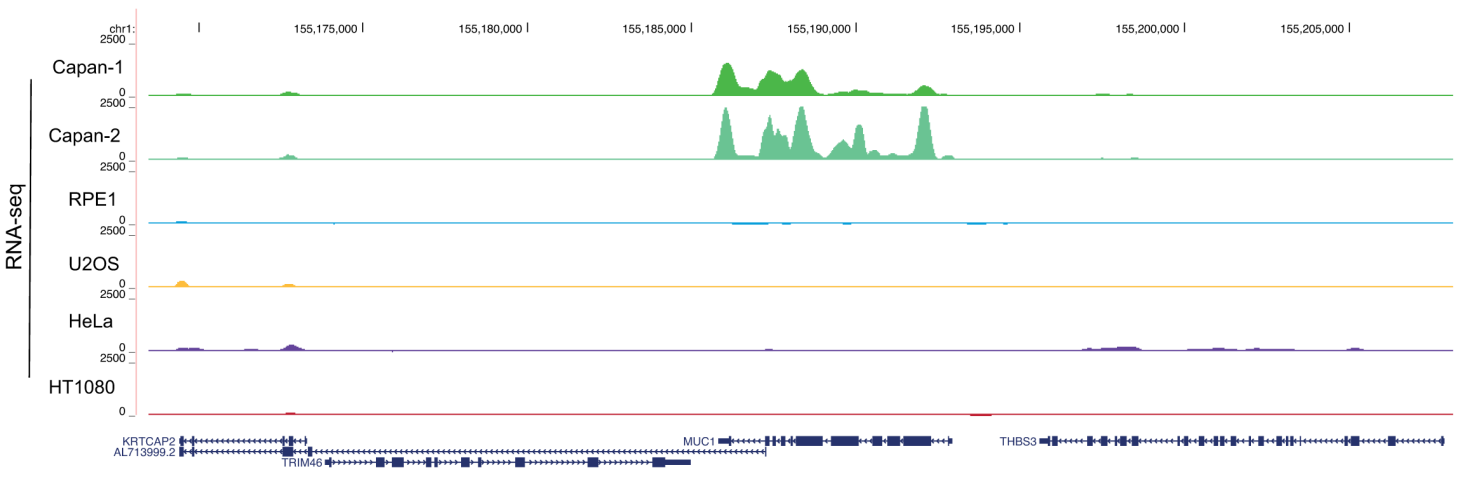

C

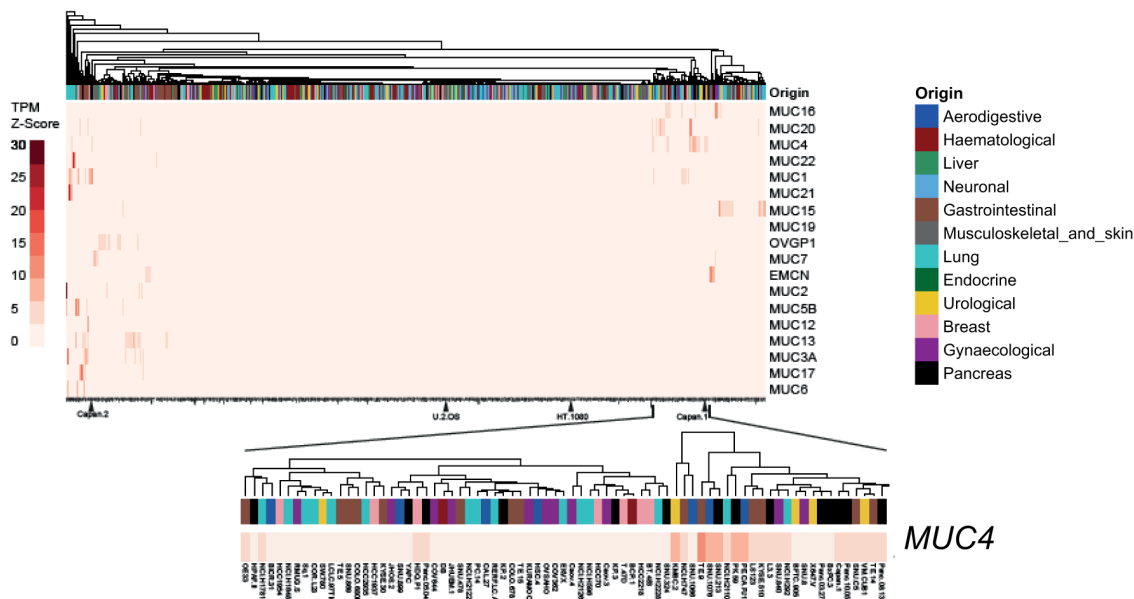

D

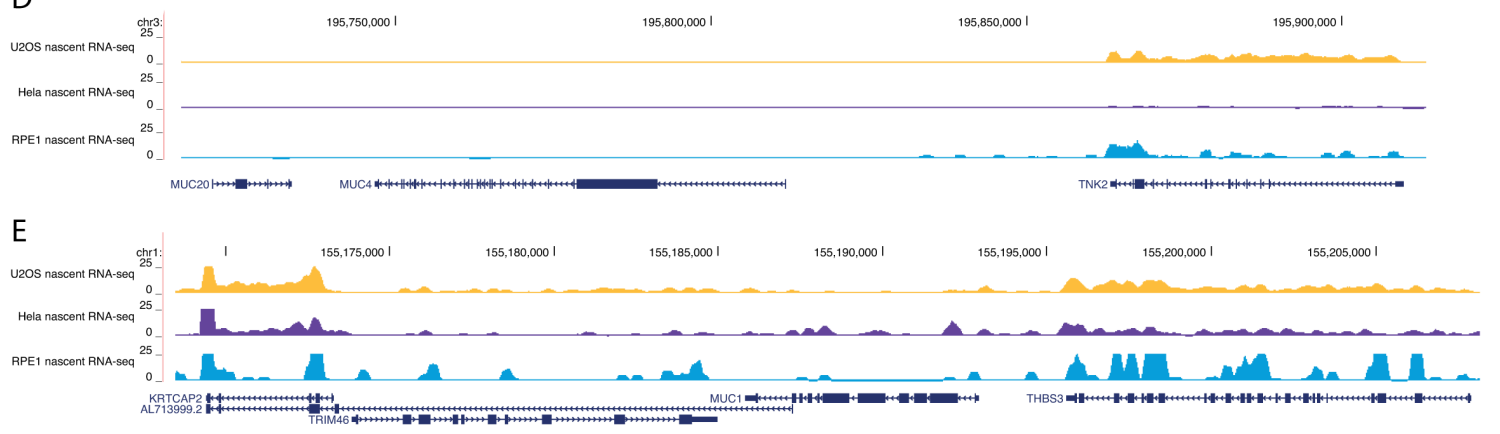

Figure 4. RNA-seq analysis for the mucin genes. RNA-seq data from mature mRNA at the (A) MUC4/MUC20 locus and (B) MUC1 locus for human cell lines; CAPAN-1 and CAPAN-2 pancreatic adenocarcinoma, RPE1, U2OS, HeLa and HT1080 fibrosarcomma cell lines. Data sources are detailed in Table 1. C) Heatmap showing z-scores for transcripts per million (TPM) for the mucin gene family obtained from RNA-seg datasets for 934 cell lines from the EBI-EMBL Expression Atlas data release 37. Cell lines were assigned an organ origin type with clustering using the default clustering method. Zoom in shows data for MUC4. D) Nascent (4SU) RNA-seq data at the MUC4/MUC20 locus in U2OS, HeLa and RPE cell lines. Data sources are detailed in Table 1. 
how meaningful the repression, reported as a consequence of dCas9 targeting at these loci, is. Consistent with previous reports (Jonckheere et al., 2004) MUC4 expression was detected in the pancreatic adenocarcinoma cell lines CAPAN-1 and CAPAN-2.

Using publicly available datasets, we also found no evidence of mRNA expression from these mucin genes in U2OS cells or in HeLa cells (Figure 4A and B), even though visualisation of MUC4 transcripts using dCas13 and single molecule FISH has been recently reported in live and fixed HeLa cells, respectively (Yang et al., 2019).

Analysis of RNA-seq data for 934 cell lines, including U2OS and CAPAN cells (Figure 4C), confirmed highly restricted expression of the entire mucin gene family, with MUC4 expression detected in a small number of cell lines, including CAPAN-1 and 2, of gastrointestinal, urological and pancreatic origin. No expression of any mucin gene was detected in U2OS cells.

To ascertain if despite the absence of stable mucin mRNAs, there might still be transcription from the MUC4/MUC20 loci in the cell lines examined, we assessed nascent RNA-seq (4-thiouridine/4SU-seq) data from U2OS and HeLa cells and 5-ethynyl uridine/EU-seq from RPE cells. No evidence for nascent transcription was detected from MUC4/MUC20 in data from any of these cell lines (Figure 4D).

\section{Discussion}

The ability to detect endogenous gene loci in mammalian cells is an important goal and, the ability to study these genes during the act of transcription is key to understanding both the chromatin dynamics associated with transcription and the spatial organisation of these genes relative to the components of the transcriptional machinery. Whilst many groups are exploring ways to improve the signal:noise problems inherent in visualising a single-copy gene, the mammalian MUC4 gene could be an excellent model since the repetitive nature of the sequences in exon 2 and intron 3 maximises the detection of fluorescent signal from molecules targeted to this locus - e.g. through dCas9 or TALEs (Chen et al., 2013) (Figure 1).

This has been the basis for studies reporting repression of the MUC4 (and MUC1) genes upon binding by dCas9 (Chen et al., 2013) and visualisation of MUC4 transcripts using dCas13 (Yang et al., 2019). However, our data reported here suggest a re-examination of the conclusions from these previous reports is required in order to understand, for example, whether these discrepancies arise from breakthrough transcription in a very small fraction of cells, from differences between batches of cell lines, or from differences in the ability to detect transcription using different methods. Our data also suggest that other cell lines that robustly express mucin genes might be a better system to employ for live cell imaging studies.
Data availability

Underlying data

NCBI Gene Expression Omnibus: Sources of H3K4me3. Accession number GSM871043; https://identifiers.org/geo: GSM871043.

NCBI Gene Expression Omnibus: Sources of H3K36me3. Accession number GSM788076; https://identifiers.org/geo: GSM788076.

NCBI Gene Expression Omnibus: Sources of mRNA RNA-seq data for Capan-1 and 2 cells. Accession number GSE79669; https://identifiers.org/geo:GSE79669.

NCBI Gene Expression Omnibus: Sources of mRNA RNA-seq data for U2OS. Accession number GSE162163; https://identifiers. org/geo:GSE162163.

NCBI Gene Expression Omnibus: Sources of mRNA RNA-seq data for RPE1. Accession number GSE98541; https://identifiers. org/geo:GSE98541.

NCBI Gene Expression Omnibus: Sources of mRNA RNA-seq data for HeLa. Accession number GSE90235; https://identifiers. org/geo:GSE90235.

NCBI Gene Expression Omnibus: Sources of mRNA RNA-seq data for HT1080. Accession number GSE78653; https://identifiers. org/geo:GSE78653.

NCBI Gene Expression Omnibus: Sources of nascent RNA-seq data for U-2OS. Accession number GSE162264; https://identifiers. org/geo:GSE162264.

NCBI Gene Expression Omnibus: Sources of nascent RNA-seq data for RPE1. Accession number GSE137448; https://identifiers. org/geo:GSE137448.

NCBI Gene Expression Omnibus: Sources of nascent RNA-seq data for HeLa. Accession number GSE128753; https://identifiers. org/geo:GSE128753.

\section{Acknowledgements}

NA conducted most of the experiments, data analysis and presentation, and was responsible for methodology and original draft preparation, IW assisted with and validated RT-PCR, SB assisted with FISH and karyotyping, SCB conducted analysis of publicly available datasets, WAB was responsible for conceptualization and funding acquisition, data presentation and wrote the manuscript. We thank Ling-Ling Chen (Shanghai Institute of Biochemistry and Cell Biology) and Bo Huang (University of California, San Francisco) for helpful discussion and for sharing data with us. 
Alexander JM, Guan J, Li B, et al.: Live-cell imaging reveals enhancerdependent Sox2 transcription in the absence of enhancer proximity. elife. 2019; 8: e41769.

PubMed Abstract | Publisher Full Text | Free Full Text

de Almeida SF, Grosso AR, Koch F, et al.: Splicing enhances recruitment of methyltransferase HYPB/Setd2 and methylation of histone H3 Lys36. Nat Struct Mol Biol. 2011; 18(9): 977-983.

PubMed Abstract | Publisher Full Text

Chaturvedi P, Singh AP, Batra SK: Structure, evolution, and biology of the MUC4 mucin. FASEB J. 2008; 22(4): 966-981.

PubMed Abstract | Publisher Full Text | Free Full Text

Chen B, Gilbert LA, Cimini BA, et al.: Dynamic imaging of genomic loci in living human cells by an optimized CRISPR/Cas system. Cell. 2013; 155(7): 1479-1491.

PubMed Abstract | Publisher Full Text | Free Full Text

Cheng AW, Jillette N, Lee $\mathrm{P}$, et al.: Casilio: A versatile CRISPR-Cas9-Pumilio hybrid for gene regulation and genomic labeling. Cell Res. 2016; 26(2): 254-257.

PubMed Abstract | Publisher Full Text | Free Full Text

Chubb JR, Boyle S, Perry $\mathrm{P}$, et al:: Chromatin motion is constrained by association with nuclear compartments in human cells. Curr Biol. 2002 12(6): 439-445.

PubMed Abstract | Publisher Full Text

Fantes JA, Bickmore WA, Fletcher JM, et al: Submicroscopic deletions at the WAGR locus, revealed by nonradioactive in situ hybridization. Am J Hum Genet. 1992; 51(6): 1286-1294.

PubMed Abstract | Free Full Text

Gao X, Tsang JCH, Gaba F, et al:: Comparison of TALE designer transcription factors and the CRISPR/dCas9 in regulation of gene expression by targeting enhancers. Nucl Acids Res. 2014; 42(20): e155-e155.

PubMed Abstract | Publisher Full Text | Free Full Text

Germier T, Kocanova S, Walther N, et al:: Real-Time Imaging of a Single Gene Reveals Transcription-Initiated Local Confinement. Biophys J. 2017; 113(7): 1383-1394.

PubMed Abstract | Publisher Full Text | Free Full Text

Gu B, Swigut T, Spencley A, et al.: Transcription-coupled changes in nuclear mobility of mammalian cis-regulatory elements. Science. 2018; 359(6379): 1050-1055.

PubMed Abstract | Publisher Full Text | Free Full Text

Jacome A, Fernandez-Capetillo O: Lac operator repeats generate a traceable fragile site in mammalian cells. EMBO Rep. 2011; 12(10): 1032-1038.

PubMed Abstract | Publisher Full Text | Free Full Text

Jonckheere N, Perrais M, Mariette C, et al.: A role for human MUC4 mucin gene, the ErbB2 ligand, as a target of TGF-beta in pancreatic carcinogenesis. Oncogene. 2004; 23(34): 5729-5738.

PubMed Abstract | Publisher Full Text

Kim S, Kim H, Fong N, et al.: Pre-mRNA splicing is a determinant of histone H3K36 methylation. Proc Natl Acad Sci U S A. 2011; 108(33): 13564-13569. PubMed Abstract | Publisher Full Text | Free Full Text

Knight SC, Xie L, Deng W, et al.: Dynamics of CRISPR-Cas9 genome interrogation in living cells. Science. 2015; 350(6262): 823-826. PubMed Abstract | Publisher Full Text

Livak KJ, Schmittgen TD: Analysis of relative gene expression data using real-time quantitative PCR and the 2(-Delta Delta C(T)) Method. Methods. 2001; 25(4): 402-408.

PubMed Abstract | Publisher Full Text

Ma H, Tu LC, Naseri A, et al.: Multiplexed labeling of genomic loci with dCas9 and engineered sgRNAs using CRISPRainbow. Nat Biotechnol. 2016; 34(5): 528-30.

PubMed Abstract | Publisher Full Text | Free Full Text

Miyanari Y, Ziegler-Birling C, Torres-Padilla ME: Live visualization of

chromatin dynamics with fluorescent TALEs. Nat Struct Mol Biol. 2013; 20(11): 1321-1324.

PubMed Abstract | Publisher Full Text

Osorio-Valeriano M, Altegoer F, Steinchen W, et al:: ParB-type DNA

Segregation Proteins Are CTP-Dependent Molecular Switches. Cell. 2019;

179(7): 1512-1524.e15.

PubMed Abstract | Publisher Full Text

Pollex T, Heard E: Nuclear positioning and pairing of X-chromosome

inactivation centers are not primary determinants during initiation of

random X-inactivation. Nat Genet. 2019; 51(2): 285-295.

PubMed Abstract | Publisher Full Text

Qin P, Parlak M, Kuscu C, et al.: Live cell imaging of low- and non-repetitive chromosome loci using CRISPR-Cas9. Nat Comms. 2017; 8: 14725.

PubMed Abstract | Publisher Full Text | Free Full Text

Ren $R$, Deng $L$, Xue $Y$, et al:: Visualization of aging-associated chromatin alterations with an engineered TALE system. Cell Res. 2017; 27(4): 483-504. PubMed Abstract | Publisher Full Text | Free Full Text

Shariati SA, Dominguez A, Xie S, et al.: Reversible Disruption of Specific Transcription Factor-DNA Interactions Using CRISPR/Cas9. Mol Cell. 2019; 74(3): 622-633.e4.

PubMed Abstract | Publisher Full Text | Free Full Text

Yang LZ, Wang Y, Li SQ, et al:: Dynamic Imaging of RNA in Living Cells by CRISPR-Cas13 Systems. Mol Cell. 2019; 76(6): 981-997.e7.

PubMed Abstract | Publisher Full Text 


\section{Open Peer Review}

\section{Current Peer Review Status:}

\section{Version 1}

Reviewer Report 03 November 2021

https://doi.org/10.21956/wellcomeopenres.19041.r46425

(C) 2021 Chubb J. This is an open access peer review report distributed under the terms of the Creative Commons Attribution License, which permits unrestricted use, distribution, and reproduction in any medium, provided the original work is properly cited.

\section{Jonathan Chubb}

MRC Laboratory for Molecular Cell Biology and Department of Cell and Developmental Biology, University College London, London, UK

This is a very interesting contribution to the technology development of Cas9/Talen tools for imaging and controlling gene expression and chromatin dynamics. A variety of approaches have been used over the past 35 years, starting with the imaging of DAPI and EtBr stained nuclei, through to the integration of repeats of bacterial repeats and their detection using repeat binding proteins. These methods have limits in resolution and potential disruption of the underlying template. The potential to detect single loci and their products without disrupting the underlying locus promises more precise measurements of a more physiological chromatin state. Many initial studies using Talens and Cas9 tools have focussed on the MUC4 gene, as its repetitive nature allows the accumulation of more fluorescence at the site of transcription. This new study indicates that MUC4 is not expressed in most of the cell lines under study, which limits the interpretation of any chromatin dynamics inferred, and the magnitude of any unwanted effects on the endogenous locus inferred using Cas9 and Talens to image chromatin.

The manuscript is generally well written, and the conclusions unequivocal. The statistical analysis is limited, but the data are so clear, this probably warrants little consideration. The text in the legend for Figure 4E is missing and should be added. Perhaps also some discussion of an alternative target for imaging, such as an abundantly expressed gene with lots of repeats, such as Filaggrin.

Is the work clearly and accurately presented and does it cite the current literature? Yes

Is the study design appropriate and is the work technically sound? Yes

Are sufficient details of methods and analysis provided to allow replication by others? Yes 


\section{If applicable, is the statistical analysis and its interpretation appropriate? Yes}

Are all the source data underlying the results available to ensure full reproducibility? Partly

Are the conclusions drawn adequately supported by the results?

Yes

Competing Interests: No competing interests were disclosed.

Reviewer Expertise: Single cell gene expression, imaging, development.

I confirm that I have read this submission and believe that I have an appropriate level of expertise to confirm that it is of an acceptable scientific standard.

Author Response 17 Nov 2021

Wendy Bickmore, Institute of Genetics and Cancer, University of Edinburgh, Edinburgh, UK

We thank the reviewer for pointing out the omission in the legend to Figure $4 \mathrm{E}$, this has now been corrected in a revised version. We also thank the reviewer for pointing out other genes with internal tandem repeats, and we have now added a statement about alternative gene targets such as Filaggrin .

Competing Interests: No competing interests were disclosed.

Reviewer Report 22 October 2021

https://doi.org/10.21956/wellcomeopenres.19041.r46423

(c) 2021 Sexton T. This is an open access peer review report distributed under the terms of the Creative Commons Attribution License, which permits unrestricted use, distribution, and reproduction in any medium, provided the original work is properly cited.

\section{Thomas Sexton}

CNRS UMR7104, INSERM U1258, IGBMC, Université de Strasbourg, Strasbourg, France

This clearly written report convincingly shows lack of MUC4 expression in the cell lines used in previous live imaging studies, and the authors rightly highlight the care needed in developing and validating such studies in the future.

It would be nice if the authors could be a bit more explicit in their take on what this means for the potential impact of dCas9 and/or TALEs on expression of the genes they are being used to image. Are there other cases unrelated to MUC4 in the literature, showing transcription perturbation by these tools, and are they more believable? Or do the authors believe that the impact of the tools 
on transcription has not yet been adequately tested?

Is the work clearly and accurately presented and does it cite the current literature? Yes

Is the study design appropriate and is the work technically sound?

Yes

Are sufficient details of methods and analysis provided to allow replication by others? Yes

If applicable, is the statistical analysis and its interpretation appropriate?

Not applicable

Are all the source data underlying the results available to ensure full reproducibility? Yes

Are the conclusions drawn adequately supported by the results?

Yes

Competing Interests: No competing interests were disclosed.

Reviewer Expertise: Molecular biology; nuclear organisation

I confirm that I have read this submission and believe that I have an appropriate level of expertise to confirm that it is of an acceptable scientific standard.

Author Response 16 Nov 2021

Wendy Bickmore, Institute of Genetics and Cancer, University of Edinburgh, Edinburgh, UK

We thank this reviewer for these comments. We do indeed think that the impact of dCas9 or TAL effector tools on DNA templated transactions, including transcription, have not been systematically tested to date.

Competing Interests: No competing interests were disclosed. 